\title{
Applying the Social Norms Approach to Help Seeking Behavior in the Military
}

Janette Hamilton

Virginia Commonwealth University

Follow this and additional works at: https://scholarscompass.vcu.edu/etd

Part of the Counseling Psychology Commons

(C) The Author

\section{Downloaded from}

https://scholarscompass.vcu.edu/etd/3033

This Thesis is brought to you for free and open access by the Graduate School at VCU Scholars Compass. It has been accepted for inclusion in Theses and Dissertations by an authorized administrator of VCU Scholars Compass.

For more information, please contact libcompass@vcu.edu. 


\section{APPLYING THE SOCIAL NORMS APPROACH TO HELP SEEKING BEHAVIOR IN THE MILITARY}

A thesis submitted in partial fulfillment of the requirements for the degree of Master of Science at Virginia Commonwealth University

\section{By: JANETTE HAMILTON}

Masters of Arts in Psychology, The College at Brockport, State University of New York, 2011

Bachelor of Arts in Psychology, Fontbonne University, 2009

Director: Steven Danish, Ph.D.

Professor of Psychology

Department of Psychology

Virginia Commonwealth University

Richmond, Virginia

May 2013 


\section{Table of Contents}

\section{Page}

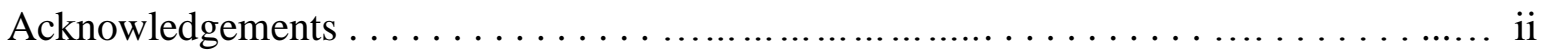

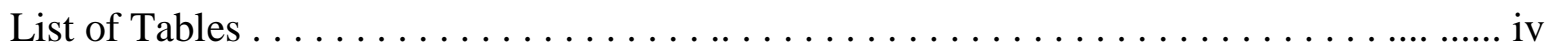

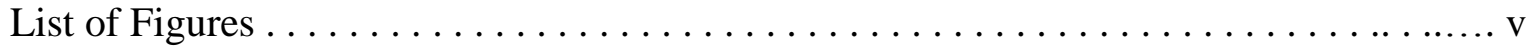

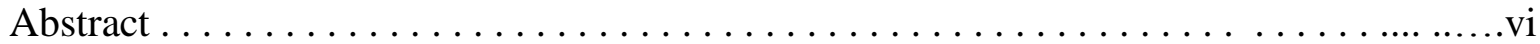

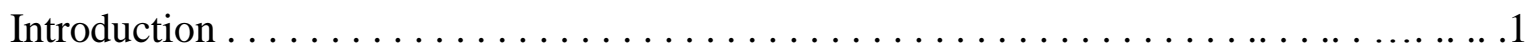

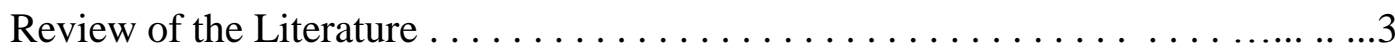

Stigma and Help Seeking Behavior $\ldots \ldots \ldots \ldots \ldots \ldots \ldots \ldots \ldots \ldots$

Barriers to Mental Health Care in the Military............................5

Combating Stigma.................................. 11

Social Norms Approach: The Conceptual Framework for this Study................12

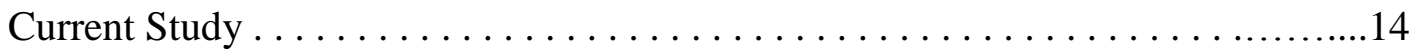

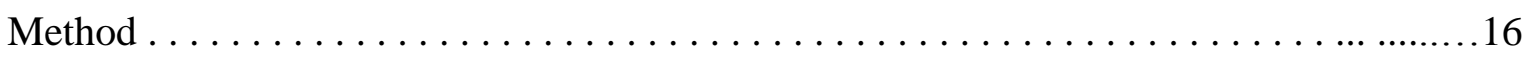

Participants ................................ 16

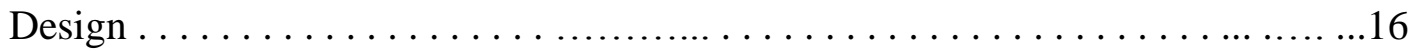

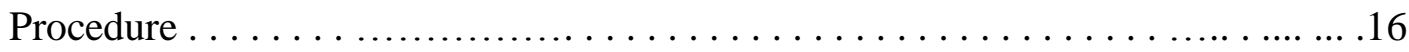

Assessment/Measures . . . . . . . . . . . . . . . . . . . . . . . 18

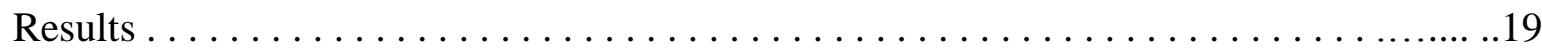

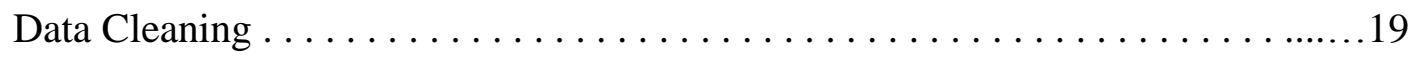

Hypothesis Testing . . . . . . . . . . . . . . . . . . . . 19

Exploratory Analyses. . . . . . . . . . . . . . . . . . . . . . 28

Discussion . . . . . . . . . . . . . . . . . . . . . . . . . . 29

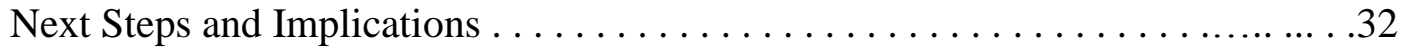




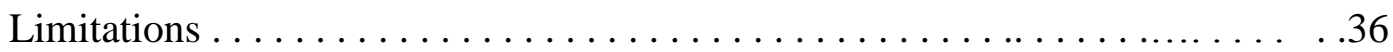

Final Thoughts ..................................

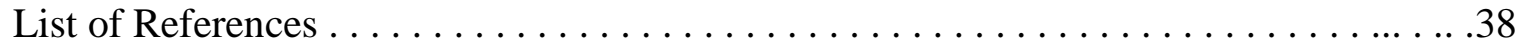

Appendices ...................................... . . . . .

A Reality and Perception Questions.....................41

B Counterbalanced Reality and Perception Questions. . . . . . . . .....45

C Demographic Questions \& Utilization of Mental Health Services..........49

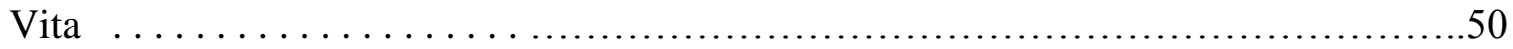




\section{List of Tables}

Page

Table 1. Participant Demographics and Characteristics................. 17

Table 2. Correlations between Reality and Perception Stigma-Related Barriers to care......................................................22

Table 3. Correlations between Willingness to Seek Help and Reality and Perception Variables..........................................................24

Table 4. Summary of Multiple Regression Analysis for Reality Stigma-Related Barriers Predicting Personal Willingness to Seek Help....................25

Table 5. Summary of Multiple Regression Analysis for Perception Stigma-Related Barriers to Care Predicting Personal Willingness to Seek Help.............26

Table 6. Summary of Means and Standard Deviations of Demographic Variables in Relation to Willingness to Seek Help........................ . 28 


\begin{abstract}
APPLYING THE SOCIAL NORMS APPROACH TO HELP SEEKING BEHAVIOR IN THE MILITARY
\end{abstract}

\author{
By Janette Ann Hamilton, M.A.
}

A thesis submitted in partial fulfillment of the requirements for the degree of Master of Science at Virginia Commonwealth University.

Virginia Commonwealth University, 2013

Major Director: Steven Danish, Ph.D.

Professor, Counseling Psychology

OBJECTIVE: The study assessed the applicability of the social norms approach to helpseeking behavior in the military by exploring whether Service Members are affected by perceptions of peers' beliefs about stigma related barriers to mental health care. METHOD: Data were collected from members of the Virginia National Guard $(\mathrm{N}=84)$ during Yellow Ribbon events. Using surveys, Service Members' own perceptions and their perceptions of their peers' beliefs about barriers to seeking psychological care were gathered. RESULTS: Participants' own beliefs about barriers to care were positively correlated with perceptions of peers' beliefs. Variance in help-seeking status was better accounted for by participants' own beliefs on stigma-related barriers to care, but perceptions of peers' beliefs were also correlated with help-seeking status. CONCLUSION: Personal costs of seeking help according to personal and perceptions of peers' beliefs are explored, as well as implications, next steps for future research, and limitations. 
Applying the Social Norms Approach to Help Seeking Behavior in the Military According to Tanielian \& Jaycox (2008) in their RAND Report titled, Invisible Wounds of War: Psychological and Cognitive Injuries, Their Consequences, and Services to Assist Recovery, over 600,000 Soldiers, Marines, and Airmen are suspected of suffering from Traumatic Brain Injury (TBI), Posttraumatic Stress Disorder (PTSD), or major depression following one or more deployments supporting Operation Iraqi Freedom in Iraq (OIF) and/or Operation Enduring Freedom in Afghanistan (OEF). However, less than half of these individuals have, or will seek professional help for their service-related psychological injuries. An overwhelming trend has emerged throughout studies conducted on postdeployment health. Service Members are consistently screening positive for mental health concerns, yet failing to seek care from behavioral health providers.

The Department of Defense (DoD) has also recognized this situation, and indicated that a substantial number of Servicemen and Women are not seeking the help they need due to a fear of the negative impact that it may have on their career, as well as how the Service Member may be viewed by others for seeking help. Thus, the benefits that would likely follow from treatment of psychological distress do not seem to outweigh the stigma associated with seeking help for many members of our Armed Forces. The DoD suggested an educational campaign be implemented to reverse this widespread ideology, and thus increase the utilization of mental health services across the military force (Department of Defense, Task Force on Mental Health, 2007). Researchers and practitioners alike have answered this call with the development of various programs to encourage Service Members 
to seek psychological care, yet none have found a solution that would be practical for the vast amount of people needed to be served.

As will be seen, the negative perceptions of seeking mental health treatment as a current or former Service Member go beyond rank, branch of service, or the number of years served in the military. With much of the focus in recent literature on the prevalence of diagnoses such as PTSD and TBI in returning Veterans, the need for mental health services are unquestionable; however the pervasiveness of stigma-related barriers to care warrants further exploration, along with viable solutions that will help to assuage the apprehension associated with seeking psychological care for Service Members.

The aims of this exploratory study are twofold: (1) to assess the stigma-related barriers that reduce the likelihood that a current or former member of the Armed Forces will seek psychological care; and (2) to assess the applicability of a social-norms approach as a possible intervention to reduce the stigma associated with mental health care in the military, and thus increase the utilization of psychological services by uniformed personnel and Veterans. It is the hope of the researcher that a more thorough understanding of the extensiveness of stigmatized views of mental health care for Service Members, as well as the recognition of the role that a peers' attitudes and beliefs towards psychological care might play in determining help-seeking behavior, will lead to the development of a comprehensive plan to ease the apprehension of seeking help for our Veterans. 


\section{Review of the Literature}

I will begin by introducing the concept of stigma in seeking mental health treatment, and follow by presenting the recent research that has examined the role that stigmatized views of mental illness and mental health care have played in deterring Service Members from seeking mental health services. I will then provide a brief review of the programs and theories that have recently been proposed or adopted for use with OIF and OEF veterans to combat stigma-related barriers to care. Further, I will present the social-norms approach as a means to challenge and modify individuals' attitudes and behaviors, and explain how this theory can be applied to reduce the stigma associated with seeking mental health care within a military population. I will end by providing the rationale for the current study, along with expanding on the aims of the current research.

\section{Stigma \& Help Seeking Behavior}

Stigma has been defined as "an attribute that is deeply discrediting" (Goffman, 1963, p. 13) and as a negative and erroneous attitude about a person that results in a prejudice or negative stereotype (Corrigan and Penn, 1999). It may occur at all stages of an illness, from help-seeking to treatment and discharge (Byrne, 2001) and it has been suggested that stigma can be more devastating, life-limiting and longer-lasting than the primary illness itself (Schulze, Richter-Werling, Matschinger, \& Angermeyer, 2003).

The presence of stigma--related beliefs towards mental health has become a strong indicator of whether or not an individual will seek help both in the community and in military settings. Corrigan (2004) defined two kinds of stigma: public stigma--the perception (held by others) that a person who seeks psychological treatment is "crazy"; and self-stigma--the perception (held by the individual) that the need for psychological help is a sign of weakness. 
The Department of Defense (DoD) hopes that most peers, supervisors (both military and civilian) and family members do not believe in the public stigma statement; however, Service Members believe that most of these groups do believe the public stigma statement and unfortunately their fears are often supported (Danish, et al., in press).

By assigning negative attributes to individuals with a mental health diagnosis, society reinforces the process of self-stigma. In an attempt to separate themselves from a label of being psychologically unfit, individuals tend to avoid anything that may associate them with this negative label, such as needing to seek help. This in turn leads to a segment of the population that is living each day with mental health or behavioral problems that goes untreated because of a fear of reprisal from others for taking the proper steps to get help.

Vogel, Wade, and Hackler (2007) explored the self and public stigma theory in a study addressing how negative attitudes and beliefs towards mental health affect one's willingness to seek professional help when facing distressing feelings and interpersonal conflicts. The researchers uncovered that not only did public perceptions strongly relate to one's self-stigma, but also that self-stigma in turn predicted one's views towards, and desire to seek mental health counseling. Similar to Corrigan's perspective, the perception that individuals have on how those around them view psychological care can significantly influence their decision to pursue services that may be vital to their well-being (Vogel, Wade, \& Hackler, 2007).

Members of the military are not immune to the effect that public stigma and selfstigma have on help seeking behavior. In fact, it is possible that the climate that the military creates regarding mental health might make matters worse for those in the Armed Forces. There are numerous regulations and protocols for "dealing" with mental health issues in the 
U.S. military, which go beyond the scope of this paper. However, when discussing stigma in terms of an organized system such as the military, it is important to make a distinction between the necessary rules and laws that govern how mental illness is handled, and when certain action taken towards those with mental health issues become biased or unjustifiable for the individual suffering from a mental health issue. Corrigan, Markowitz, and Watson (2004) point out that there is a definitive line that separates active discrimination as opposed to protocol for dealing with those with mental health disorders in the work place or an institutional setting. Limiting one's rights in certain arenas due to mental health concerns can be the result of an attempt to protect individuals from themselves and others; as opposed to actively discriminating against someone with a mental health diagnosis. This becomes quite relevant when working within the military structure. For example, there are safety and security reasons for why an individual who has a diagnosis of a severe and persistent mental illness may not be authorized to enlist or commission in the U.S. Army, according to standards set by the Department of Defense, (DoD, 2011). Although the policies and procedures of the U.S. Military concerning mental health are beyond the scope of this discussion, the interpretation of how those serving believe that the U.S. Armed Forces as an organization view Service Members with psychological disorders is important, because as will be seen, it is tied so strongly to one's willingness to seek psychological care.

\section{Barriers to Mental Health Care in the Military}

Since the inception of OIF and OEF, researchers in the behavioral health field have been scrambling to assess the rate at which Service Members are returning with conditions such as PTSD, TBI, major depression, and other service-related mental health injuries after deployments to a combat zone. Increased awareness of disorders of these types in veterans, 
as well as rising suicide rates within the Armed Forces have become a strong reminder of the toll that the United States' involvement in these wars has taken on our troops. It has also increased concerns over the low rate at which Service Members are taking the initiative to seek mental health services when they are suffering from psychological distress (Nash, Krantz, Stein, Westphal, \& Litz, 2011). Studies focusing on this dilemma have uncovered two common types of reasons, or as they are referred to, barriers, toward seeking mental health treatment as a member of the Armed Forces (Tanielian \& Jaycox, 2008). These include logistical barriers, as well as cultural or institutional barriers. Logistical barriers include reasons such as an inability to secure time off from work to visit a mental health care provider, not knowing where to seek treatment, or not having the financial resources necessarily to pursue this type of health service. The second type of barrier includes institutional, or what is often referred to as cultural barriers. These include instances where individuals choose not to seek help due to stigmatized views of believing they are weak (selfstigma), or fear of perceived negative views by others if they seek care (public stigma). In the military, this might include individuals believing their unit leader would look down upon them for seeking mental health care. It also includes the possibility that seeking psychological care would adversely affect one's career or relationship with the unit (Tanielian \& Jaycox, 2008). Thus, individuals also believe both in self and public stigma. In a large-scale study in 2004, Hoge et al. set out to survey thousands of Service Members before and after deployment to either Iraq or Afghanistan to assess the prevalence of symptoms related to various mental health problems including PTSD, major depression, suicidal ideation, and other psychological disorders. More unique to the field at the time was the researchers' assessment of current and prior utilization of mental health care by Soldiers 
and Marines, the intent to seek treatment, and most importantly the reasons why an individual would be hesitant to seek such treatment. Results indicated that for those who screened positive for a mental health disorder, only $23-40 \%$ had seen a behavioral health provider in the past year, and less than half of the individuals with possible diagnoses indicated that they were interested in receiving professional help. Further, those who met screening criteria for a mental health disorder were twice as likely to cite institutional or cultural barriers versus logistical barriers for not seeking psychological care (Hoge, et al., 2004). Common reasons for not seeking care included the perception that others would view the Service Member as "weak" for doing so, or that one's chain of command might treat him or her differently for pursuing psychological help (Hoge, et al., 2004). In the 2008 RAND report on mental health care in the military, Tanielian and Jaycox (2008) replicated these findings with Service Members across the four major branches involved in the OEF and OIF conflicts. After surveying over 1900 Service Members from 24 geographical regions, they found that a majority of Veteran respondents were concerned with the effect that seeking mental health treatment would have on their career, including the possibility of limitations in their future job assignments in the Armed Forces. The study also found that $45 \%$ of the respondents indicated concerns over possible "side effects" from the use of drug therapy in treating mental health concerns, while a quarter of the Veterans believed that mental health care is not "effective". The authors indicated that logistical barriers were also a concern of Service Members, but were not as prominent for the participants as the cultural or institutional barriers provided (Tanielian \& Jaycox, 2008).

Recently, researchers investigated the difference in reporting of psychological symptoms when Soldiers were given the opportunity to reply anonymously to a questionnaire 
mirroring the Post Deployment Health Assessment (PDHA). The PDHA is administered to Service Members directly after combat deployments, and includes questions about mental health and well-being designed to detect the presence of a psychological disorder. In a group of over 17000 Soldiers from an Army combat brigade recently returned from deployment, researchers found that depression, suicidal ideation, PTSD, and interest in receiving care were 2 to 4 times higher after an anonymous mental health assessment, compared to results from the traditional PDHA. Further, 20\% of solders screening positive for depression or PTSD expressed they were uncomfortable being honest in their responses on the PDHA screening (Warner, et al., 2011). Findings such as these further validate the presence of stigma related to mental health as well as an unwillingness to seek help in the military.

Researchers have attempted to unpack some of the reasons why individuals serving in the Armed Forces hold such stigmatized views of mental health treatment. One study looked at the interaction between unit cohesion and leadership for answers. They found that as a Soldier's perception of the closeness of their unit increased, as well as the confidence they had in their relationship with their commander, levels of stigmatized barriers to care rated by the person decreased (Wright, et al., 2009). It is not surprising that the Soldiers and Marines endorse more stigmatized views of help-seeking when they felt less connected with to their reference group (their unit), and their leaders, who arguably make the strongest impact on their development and behavior during their time in service. What this seems to indicate is that if Service Members do not feel supported by those who mean the most to them while deployed, they are less likely to seek help for their problems, be they psychological or otherwise. This perspective is further validated by the numerous studies that have found fear of reprisal from other Service Members and commanders as strong indicators for why 
individuals in the Armed Forces are not seeking mental health treatment (Kim, Thomas, Wilk, Castro, \& Hoge, 2010; Hoge et al, 2004; Tanielian \& Jaycox, 2008).

The studies cited above all were with Active Duty Service Members. Reserve and National Guard components of the U.S. Armed Forces have until these two conflicts lived under vastly different circumstances. They have lived stateside, generally had full-time jobs, and their military training was limited to one weekend per month and two weeks in the summer. They were often called "weekend warriors." However, due to the nature of the current conflicts, the National Guard has been called away from their traditional duty of securing and protecting the home front, to serve overseas in large numbers in Iraq and Afghanistan. As of July 31, 2011 a total of 350,071 National Guard Members had been deployed and as of 2011, 48,024 were presently deployed (DMDC, 2011). The unique stressors these individuals have faced due to being deployed for the first time has sometimes resulted in personal and family problems that may be alleviated with psychological help. How, if at all, would the military culture and its norms be different for National Guard Soldiers as opposed to their Active Duty counterparts with regard to their willingness to seeking help? Interestingly, there did not seem to be significant differences.

When Active Duty and National Guard Soldiers were both measured and compared on their feelings towards seeking mental health services, the National Guard Soldiers surveyed overwhelmingly identified many of the same barriers as the Active Duty Soldiers did. These similarities included such reasons as worry over how unit leaders and fellow Service Members would view them if they sought help, that seeking help would be too "embarrassing", and that seeking psychological care would harm their careers (Kim et al., 2010). 
National Guard Soldiers who screen positive for a disorder such as PTSD have also been shown to rate barriers to care related to stigma as the main reason they do not seek help, similar to the barriers identified by Active Duty Soldiers (Gorman, Blow, Ames, Reed, 2011; Pietrzak, Johnson, Goldstein, Malley, \& Southwick, 2009; Hoge et al., 2004). One difference that exists between the two groups is the process by which mental health services are acquired. Active Duty Service Members typically live on or near military installations, and thus have access to military treatment facilities (MTF), in addition to civilian providers, and VA hospitals. Those in the National Guard are said to be more "isolated" than their Active Duty counterparts because they are living in various geographic locations across the country, and typically do not reside near an MTF (Gorman et al., 2011). This can present unique difficulties for members of the National Guard when logistical barriers, such as not living on or near a military installation, the overwhelmed VA systems, or a lack of civilian providers with experience treating military personnel are intermixed with institutional barriers, such as stigma. Particularly, it can further reduce the likelihood that these Service Members will seek counseling when it is needed.

Another difference in help seeking behavior between Active Duty and Reserve Components is some of the solutions that have been recommended or put in place by the military to increase Service Members' willingness to visit a behavioral health professional. For example, one method that the DoD has adopted is training within units the senior enlisted Service Members, chaplains, and mental health providers in Combat and Operational Stress Control (COSC). COSC involves educating the line leaders and care givers with tools to quickly manage and intervene in instances of severe stress, in order to prevent psychological and physical deterioration of Service Members that inhibit their war fighting abilities (Nash 
et al., 2011). This approach is certainly useful in that it provides quick and personalized mental health "check-ups" with individuals closely linked to one's units. However, its effectiveness is limited to individuals who are deployed or on Active Duty. Those in National Guard and Reserve units typically only meet collectively once a month for a weekend long "drill", unless they have been activated for a deployment. Thus, the chance for them to connect with a unit level provider, be it a mental health professional, their chaplain, or a unit leader, is limited. Further, since National Guard and Reservists are spending a majority of their time living a "civilian life", these Service Members may be more likely to seek help in a community setting (Tanielian \& Jaycox, 2008). Subsequently, an alternative method for increasing help seeking behavior and combating stigma in the military should be developed and employed so that all Soldiers, Marines, Airmen, and Veterans can be reached no matter what their affiliation is with military at their time of need.

\section{Combating Stigma}

Many pilot programs have been developed over the past few years, all with the aim of stemming the damaging effect that stigmatized views of mental illness within the military are having on rates of help-seeking behavior. Ideas have ranged from the use of Cognitive Behavioral Therapy with veterans to alter their negative attitudes and beliefs towards psychological illness and care (Stecker, Fortney, \& Sherbourne, 2011), to the use of peer-topeer programs involving phone outreach for Service Members returning from deployment to help normalize issues they may be having during reintegration periods post-deployment, and encourage utilization of mental health services (Greden, Valenstein, Spinner, Blow, Gorman, Dalack, Marcus, \& Kees, 2010). Others have called for a change in the way we diagnose and explain the etiology of commonly seen disorders in veterans, pushing for a medicalized view 
of certain diagnoses such as PTSD, so that Service Members and Veterans will be less likely to self-blame and refuse help for their mental health problems (Nash, Silva, \& Litz, 2009). While each of these approaches may be useful in combating mental health stigma in the military, it seems clear that a more comprehensive approach must be undertaken to try and change the deeply rooted beliefs that have perpetuated negative views towards mental illnesses and mental health treatment in this population.

\section{Social Norms Approach: The Conceptual Framework for this Study}

According to Berkowitz (2004), our behavior is guided by the cues we take from those in our reference or peer groups. Thus, we act according to the norms that we perceive to be relevant according to those with whom we most identity. However, our perceptions about the way that others think and behave are often inaccurate. These misperceptions can result in the pursuit of behaviors that are contrary to one's well-being. Underestimating the rate at which individuals in our reference groups engage in "healthy" behaviors, and overestimating how often "problem" behaviors are engaged in, can result in one pursuing maladaptive ways of living.

Perkins and Berkowitz (1986) used this theory to study whether they could moderate college students' drinking behavior. Students were asked questions about their own drinking behavior, including how much and how often they consumed alcohol. They were then asked to rate the extent to which they believed that their peers were consuming alcoholic beverages. Results indicated that students consistently over-estimated the average amount of alcohol their peers consumed over a given time period. In fact, the reality was that more conservative alcohol use was the norm in this group of college students. Similar findings were found with a sample of 76,000 students in colleges across the country (Perkins, 2007). As predicted, 
students again consistently assumed that those in their peer group were drinking at much higher rates than what they actually were. Further, it was found that one's perception of what constituted normal drinking behavior for those in their age group was a stronger predictor of drinking habits in these students than the real or true drinking behaviors of the individual's reference group. The amount and rate at which students' consumed alcohol seemed to be driven by how often they thought their peers were drinking, rather than what the actual level of consumption was across the college students surveyed.

If others' beliefs and behaviors are incongruent with one's belief, a misperception exists. By correcting misperceptions, especially when they overestimate the prevalence of a problem behavior, it is possible to modify an individual's behavior to better reflect the true habits of their peers (Berkowitz, 2004). An example of the utility of correcting perceptions of problem behaviors can be seen in an intervention by Haines \& Spear (1996) that was directed towards reducing risky drinking behavior at a large Midwestern university. These authors found that after implementing a six year, campus wide social norms campaign that presented accurate information on the drinking rates of U.S. college students, binge drinking and accidents related to alcohol consumption resulted in a significant decline in drinking rates over the six years that the campaign took place. Similar results were found at a separate university using the same intervention over a five year time period (Perkins \& Craig, 2002).

The social norms approach has also been extended to help-seeking behavior. Conley (2011) implemented this model with a large group of college students to determine if individuals were likely to be influenced by the perceptions of their peers with regard to seeking psychological care. Similar to previous studies involving alcohol research, Conley had participants answer questions about their personal perceptions on the utilization of 
psychological services, as well as questions about others in their age group's attitudes and behaviors towards seeking help. The aim was to identify if misperceptions existed between the "reality" and "perceptions" of the students on an individual and group level. The second goal was to address whether or not these misperceptions influenced the actual behavior of seeking professional help. They found that the students surveyed did significantly misperceive the beliefs of those in their peer group concerning help seeking behavior. The author also found that these misperceptions influenced the likelihood that college students would seek help themselves. The participants' decision to seek help was found to be based partly on beliefs about how others in their peer group view seeking psychological care. This study provides evidence of the disparity between the true and perceived attitudes towards the acceptability of seeking psychological care, as well as how it can influence the decision to seek help for college students.

\section{Current Study}

Based on the success of the social norms approach to identify misperceptions about help-seeking in college freshmen, the current study sought to assess whether the social norms for help-seeking in Service Members are different than they are for college freshmen. Thus, the current study sought to discover whether there are differences between self-stigma and other-stigma in Service Members in relation to help-seeking.

Research Question 1: What is the relationship between Service Members' beliefs about seeking mental health care and their peers' beliefs?

Hypothesis 1a: Service Members who believe their peers will respond negatively to the idea of seeking help from a mental health professional if they have had an emotional, relational, 
or psychological problem, will be less likely to indicate an interest in seeking psychological help themselves.

Hypothesis 1b: Service Members who believe their peers think that seeking help from a mental health professional is a sign of a personal weakness, will be more likely to believe that seeking help is a sign of a personal weakness themselves.

Hypothesis 1c: Service Members who believe their peers will lose confidence in a fellow Service Member who has sought mental health services will themselves be more likely to lose confidence in a fellow Service Member who has sought mental health services.

Hypothesis 1d: Service Members who believe their peers feel that leaders will treat a Service Member differently knowing they have sought mental health services, will themselves be more likely to treat those Service Members who have sought mental health services differently.

Hypothesis1e. Service Members that believe their peers think it is too embarrassing to seek mental health services will be more likely to think it is too embarrassing to seek mental health services themselves.

Hypothesis 1f. Service Members who believe their peers think seeking mental health services will harm their career, will be more likely to believe themselves that seeking mental health services will harm their own career.

Hypothesis 1g. Service Members who believe their peers think mental health care does not work will themselves be more likely to think that mental health care does not work.

Research Question 2: Do Service Members' perceptions of their peers' beliefs or personal beliefs about barriers to seeking mental health care predict willingness to seek psychological help? 
Hypothesis 2: Service Members' perceptions of their peers' beliefs about barriers to seeking mental health care will better predict willingness to seek psychological help above their own beliefs.

\section{Participants}

\section{Methods}

Participants $(N=84)$ included members of the Virginia National Guard participating in various Yellow Ribbon events in Virginia. See Table 1 for a summary of the demographic information for the participants.

\section{Design}

The design of this study was quantitative, utilizing a survey method for data collection. Participants were provided with paper versions of the measures, and randomly selected to receive a counterbalanced version of questionnaire. Counterbalancing the versions of the questionnaires helped to protect against ordering effects and priming. No identifying information was associated with the individual questionnaires, as participants were asked to refrain from printing their name on the questionnaire.

\section{Procedure}

Participants were recruited during two post-deployment Yellow Ribbon Reintegration Events for the Virginia National Guard. Yellow Ribbon Reintegration Events are mandated for members of the National Guard. The aim is to educate Guard Members and their Families on how to reconnect after deployments, as well as on the mental health resources available to them as members of the Guard. 
Table 1.

Participant Characteristics and Demographics

\begin{tabular}{lccc}
\hline Demographic Variables & $\boldsymbol{n}$ & $\boldsymbol{\%}$ \\
\hline Rank & & 2 & 2.5 \\
E1-E3 & 41 & 50.6 \\
E4-E6 & 15 & 18.5 \\
E7-E9 & 18 & 22.2 \\
O1-O4 & 4 & 4.9 \\
O5+ & 1 & 1.2
\end{tabular}

Total Years in Service

$\begin{array}{rcc}1-4 & 20 & 24.7 \\ 5-9 & 20 & 24.7 \\ 10-15 & 17 & 21 \\ 16-20 & 8 & 9.9 \\ 20+ & 16 & 19.8\end{array}$

Race/Ethnicity

African American $\quad 9 \quad 11.3$

Asian/Asian American $\quad 3 \quad 3.8$

Hispanic, Latino $\quad 5 \quad 6.3$

Am. Indian/Pac. Islander $\quad 2 \quad 2.5$

Middle Eastern $\quad 3 \quad 3.8$

$\begin{array}{lll}\text { White/Non-Hispanic } & 51 & 63.7\end{array}$

$\begin{array}{lll}\text { Other } & 5 & 6.3\end{array}$

Marital Status

$\begin{array}{rcc}\text { Single } & 30 & 36.6 \\ \text { Married } & 38 & 46.3 \\ \text { Divorced } & 10 & 12.2 \\ \text { Widow/Widower } & 4 & 4.9\end{array}$

Previous Mental Health

Treatment

$\begin{array}{rll}\text { Yes } & 19 & 23.2 \\ \text { No } & 63 & 76.8\end{array}$

... in the past 6 months

$\begin{array}{ccc}\text { Yes } & 5 & 6.1 \\ \text { No } & 77 & 93.9\end{array}$

... in the Past 12 months

$\begin{array}{ccc}\text { Yes } & 4 & 4.9 \\ \text { No } & 78 & 95.1\end{array}$




\section{Assessment \& Measures}

\section{Reality and Perception Questions about Seeking Psychological Help (See}

Appendix A, as well as Appendix B for the counterbalanced version). To assess the type of perceptions that the Service Members have about comrades who seek mental health care, Service Members were asked a number of questions pertaining to stigma-related barriers to care based on previous research by Hoge et al. (2004). Specifically, the questions addressed how Service Members would view a fellow Soldier if they knew that he or she had visited a mental health professional for psychological issues, as well as how they believe a leader in one's unit would view that individual for seeking help. Follow-up questions were re-phrased to allow Service Members to respond with how they themselves feel about seeking psychological care, as well as how they believe others would view them for doing so. Questions were adapted from the Hoge et al. (2004) study, and formatted to use the social norms approach of addressing perceptions about help seeking behavior.

Willingness to Seek Help (See Appendix A Question 1, and Appendix B, Question 2). In order to assess the participants' willingness to seek help, Service Members were asked to respond to the question, "If I had an emotional, relational, or psychological problem, I'd seek help from a mental health professional", with response options ranging from "Strongly Disagree" to "Strongly Agree".

Demographics (see Appendix C). Participants were asked to provide demographic information, including their ethnic background, marital status, rank, current field and Military Occupational Specialty, and total years in service. Unfortunately, as noted above, because of an omission neither the participants' gender nor age was included in the survey. 
Utilization of Psychological Services (See Appendix C). Service Members’ prior utilization of mental health services was assessed with questions asking about whether they had ever sought treatment of this kind in the past, and if so, if it had been within the past six or twelve months. Service Members' beliefs about the use of psychological services by fellow Soldiers were assessed by asking the participants to estimate the number of Service Members they knew that have sought professional psychological help, and how recently they believed these individuals sought help.

\section{Results}

\section{Data Cleaning}

The data were checked for missing responses, outliers, and normality before proceeding with the analyses. Cases that were missing scores on over $80 \%$ of the survey (excluding the demographics) were removed from the analyses. A total of five cases were removed. Missing values that did not meet the $80 \%$ criteria were replaced with the mean value of the responses for the reality and perception questions. The responses for the "reality" and "perception" questions were recoded before running the data analyses, where lower values indicate a negative response, and higher values represent a positive response to the item. Thus after recoding, a " 1 " represents a negative response, and a "7" indicates a positive response for all of the questions presented.

\section{Hypothesis Testing}

Hypothesis 1a. It was hypothesized that Service Members that believe their peers will respond negatively to the idea of seeking help from a mental health professional if they had an emotional, relational, or psychological problem, will be less likely to indicate an interest in seeking psychological help themselves. Pearson's Correlation supported this 
hypothesis, in that Service Members were significantly more likely to respond negatively to the idea of seeking mental health treatment if they perceived that their peers would respond negatively to doing so, $r(82)=.62, p<001$.

Hypothesis 1b. It was hypothesized that Service Members that believe their peers think seeking help from a mental health professional is a sign of a personal weakness will be more likely to believe that seeking help is a sign of a personal weakness themselves. Pearson's Correlation confirmed this hypothesis. Service Members were more likely to view seeking help from a mental health professional as a personal weakness, if they believed that fellow Service Members held this belief as well, $r(82)=.49, p<.001$.

Hypothesis 1c. It was hypothesized that Service Members who believe peers would lose confidence in a Soldier knowing that person has sought mental health services will themselves be more likely to indicate that they too would lose confidence in a fellow Service Member who has sought mental health treatment. This hypothesis was supported by Pearson's correlation. Service Members were more likely to lose confidence in those who have sought help from a mental health professional if they believed that their peers would also have lower confidence in a Soldier who has previously sought mental health treatment, $r(82)=.67, p<.001$.

Hypothesis 1d. It was hypothesized that Service Members who believe leaders would treat a Soldier differently knowing they have sought mental health services would do the same if they were in a leadership position themselves. Pearson's correlation confirmed the hypothesis, Service Members in a leadership position would be more likely to treat a peer differently for seeking mental health services, if they believe that other leaders would do the same, $r(82)=.55, p<.001$. 
Hypothesis 1e. It was hypothesized that Service Members who believe their peers feel it would be "too embarrassing" to seek mental health services will be more likely themselves to believe it is "too embarrassing" to seek mental health services. This hypothesis was supported by Pearson's Correlation. Service Members that perceived their peers would think it too embarrassing to seek mental health services were more likely to hold this belief themselves, $r(82)=.31, p=.004$.

Hypothesis 1f. It was hypothesized that Service Members who believe their peers think seeking mental health treatment would harm their career will be more likely to believe this idea themselves. Pearson's Correlation confirmed this hypothesis. Service Members are more likely to believe that seeking mental health treatment would harm their career if they think that fellow Soldiers also hold this belief, $r(82)=.42, p<.001$.

Hypothesis 1g. It was hypothesized that Service Members who believe their peers think mental health care does not work will themselves be more likely to believe mental health care does not work. This hypothesis was supported by Pearson's Correlation. Service Members were more likely to endorse the idea that health care does not work when they perceived their peers believed this as well, $r(82)=.62, p<.001$. (See Table 2 for a summary of correlation outcomes for hypotheses 1a through 1g). 
Table 2.

Correlations between pairs of "reality" and "perception" stigma-related barriers to care $(N=84)$

\begin{tabular}{|c|c|c|c|c|c|c|c|}
\hline Variables & $\begin{array}{c}\text { Perception } \\
1\end{array}$ & $\begin{array}{l}\text { Perception } \\
2\end{array}$ & $\begin{array}{l}\text { Perception } \\
3\end{array}$ & $\begin{array}{l}\text { Perception } \\
\quad 4\end{array}$ & $\begin{array}{l}\text { Perception } \\
5\end{array}$ & $\begin{array}{l}\text { Perception } \\
\quad 6\end{array}$ & $\begin{array}{l}\text { Perception } \\
\quad 7\end{array}$ \\
\hline $\begin{array}{l}\text { 1. Reality: Willingness to } \\
\text { seek help }\end{array}$ & $.62 * *$ & & & & & & \\
\hline $\begin{array}{l}\text { 2. Reality: Personal weakness } \\
\text { vs. personal strength }\end{array}$ & & $.49 * *$ & & & & & \\
\hline $\begin{array}{l}\text { 3. Reality: Confidence in } \\
\text { peer seeking help }\end{array}$ & & & $.67 * *$ & & & & \\
\hline $\begin{array}{l}\text { 4. Reality: Leader perception } \\
\text { of seeking help }\end{array}$ & & & & $.55 * *$ & & & \\
\hline $\begin{array}{l}\text { 5. Reality: "Embarrassing" to } \\
\text { seek help }\end{array}$ & & & & & $.31 * *$ & & \\
\hline $\begin{array}{l}\text { 6. Reality: Harmful to career } \\
\text { to seek help }\end{array}$ & & & & & & $.42 * *$ & \\
\hline $\begin{array}{l}\text { 7. Reality: Does mental } \\
\text { health care work }\end{array}$ & & & & & & & $.62 * *$ \\
\hline
\end{tabular}


Hypothesis 2. It was hypothesized that Service Members' perceptions of their peers' beliefs about barriers to seeking mental health care would better predict their willingness to seek psychological help than would their own beliefs. Correlations between willingness to seek help and each of the reality and perception variables were also explored. See Table 4 for correlations, means, and standard deviations. According to the correlation models, three stigma-related barriers were significantly correlated with personal willingness to seek help: personal beliefs on whether seeking help is a sign of a personal weakness, $r(82)=.43, p<$ 001 , perception of peers' willingness to seek help, $r(82)=.62, p<001$, and perception of peers' beliefs on whether seeking help is a sign of a personal weakness, $r(82)=.30, p<001$.

Next, multiple regression analyses were conducted to examine whether Service Members' own beliefs about barriers to seeking mental health, or their perceptions of peers' beliefs predict willingness to seek help. In the first of two multiple regression models, each of the "reality" questions pertaining to barriers to seeking mental health care were simultaneously entered in Step 1. "Reality" questions are those that asked Service Members to provide their own view of the barrier to care in question. Willingness to seek help was entered as the dependent variable. Altogether, six variables were entered as predictors in the model: If mental health is viewed as a personal weakness by the Service Members, if the Service Members would lose faith in a peer who has sought mental health treatment, if as a leader, Service Members would treat a comrade "differently" knowing that they have sought mental health treatment, if it would be "too embarrassing" to seek mental health care as a Service Member, if the Service Members believe it would harm their career to seek mental health care, and whether or not Service Members believes that mental health care "works" 
Table 3.

Correlations between willingness to seek help and reality and perception variables $(N=84)$

\begin{tabular}{|c|c|c|c|}
\hline Variables & $\begin{array}{l}\text { Reality: Willingness to } \\
\text { Seek Help }\end{array}$ & $M$ & $S D$ \\
\hline $\begin{array}{l}\text { 1. Reality: Personal Weakness } \\
\text { vs. Personal Strength }\end{array}$ & $.43 * *$ & 5.04 & 1.78 \\
\hline $\begin{array}{l}\text { 2. Reality: Confidence in peer } \\
\text { who seeks help }\end{array}$ & .03 & 5.77 & 1.55 \\
\hline $\begin{array}{l}\text { 3. Reality: Leader perception of } \\
\text { seeking help }\end{array}$ & .02 & 5.15 & 1.95 \\
\hline $\begin{array}{l}\text { 4. Reality: "Embarrassing" to } \\
\text { seek help }\end{array}$ & .17 & 5.26 & 1.67 \\
\hline 5. Reality: Harm to career & .18 & 5.36 & 1.65 \\
\hline $\begin{array}{l}\text { 6. Reality: Does mental health } \\
\text { care work }\end{array}$ & .17 & 5.75 & 1.26 \\
\hline $\begin{array}{l}\text { 7. Perception: Peer willingness } \\
\text { to seek help }\end{array}$ & $.62 * *$ & 4.20 & 1.60 \\
\hline $\begin{array}{l}\text { 8. Perception: Personal } \\
\text { Weakness vs. Personal } \\
\text { Strength }\end{array}$ & $.30 * *$ & 4.19 & 1.51 \\
\hline $\begin{array}{l}\text { 9. Perception: Confidence in } \\
\text { peer who seeks help }\end{array}$ & -.01 & 4.85 & 1.62 \\
\hline $\begin{array}{l}\text { 10. Perception: Leader perception } \\
\text { of seeking help }\end{array}$ & .02 & 4.32 & 1.93 \\
\hline $\begin{array}{l}\text { 11. Perception: "Embarrassing" } \\
\text { to seek help }\end{array}$ & .03 & 4.44 & 1.70 \\
\hline 12. Perception: Harm to career & .01 & 4.58 & 1.72 \\
\hline $\begin{array}{l}\text { 13. Perception: Does mental } \\
\text { health care work }\end{array}$ & .19 & 5.00 & 1.46 \\
\hline
\end{tabular}

$* p<.05 . * * p<.01 . * * * p<.001$ 
Together, the variables significantly predicted willingness to seek help, $F(6,77)=$ $3.19, p<.001, \mathrm{R}^{2}=.20$. See Table 5 for unstandardized and standardized coefficients from regression analysis. As indicated by $\mathrm{R}^{2}$, the "reality" perception of barriers to care accounted for $20 \%$ of the variance in willingness to seek help. Whether or not Service Members' believe seeking help is a sign of a "personal weakness" (Reality 2) was the only significant predictor in the model, $t(77)=3.78, p<.001, \beta=.427$. Whether or not a soldier would lose faith in a peer who has sought mental health treatment was not significant, $t(77)$ $=.004, p=.99, \beta=.000$, the belief that "most" leaders treat Service Members' differently knowing they have sought mental health treatment was not significant, $t(77)=-.443, p=.66$, $\beta=-.056$. Whether it would be "too embarrassing" to seek mental health treatment was not significant, $t(77)=-.126, p=.90, \beta=-.015$, Service Members' beliefs that seeking mental health treatment might harm their career was not significant, $t(77)=1.16, p=.25, \beta=.150$, and Service Members' belief that mental health care does or does not "work" was not a significant barrier, $t(77)=-.25, p=.81, \beta=-.033$

Table 4 .

Summary of Multiple Regression Analysis for "Reality" Stigma-Related Barriers Predicting Personal Willingness to Seek Help $(N=84)$

\begin{tabular}{lllllll}
\hline & & \multicolumn{2}{l}{$\begin{array}{l}\text { Unstandardized } \\
\text { Coefficients }\end{array}$} & \multicolumn{3}{l}{$\begin{array}{l}\text { Standardized } \\
\text { Coefficients }\end{array}$} \\
\cline { 2 - 5 } Model & B & SE B & Beta & t & Sig. \\
\hline 1 & (Constant) & 1.723 & 1.171 & & 1.471 & .145 \\
& Reality 2 & .489 & .129 & .427 & 3.780 & .000 \\
& Reality 3 & .001 & .174 & .000 & .004 & .997 \\
Reality 4 & -.058 & .131 & -.056 & -.443 & .659 \\
Reality 5 & -.018 & .144 & -.015 & -.126 & .900 \\
Reality 6 & .185 & .160 & .150 & 1.155 & .252 \\
Reality 7 & -.054 & .217 & -.033 & -.247 & .805 \\
\hline
\end{tabular}

a. Dependent Variable; Reality: Willingness to seek help 
In the next multiple regression model, each of the "perception" questions pertaining to barriers to seeking mental health care were simultaneously entered in Step 1 of the model. "Perception" questions are those that asked Service Members to predict how their peers would respond to the barrier in question. Willingness to seek help was again entered as the dependent variable. Altogether, six predictor variables were entered: If the Service Members' believe their peers would or would not view seeking mental health treatment as a personal weakness, if Service Members' peers would lose faith in a soldier who has sought mental health treatment, if the Service Members' peers believe leaders would treat a comrade "differently" knowing they have sought mental health treatment, and if their peers believes it would be "too embarrassing" to seek mental health care, whether Service Members believe their peers think it would harm one's career in the military to seek mental health treatment, and if Service Members believe that their peers think mental health care does or does not "work" (See Table 5 for unstandardized and standardized coefficients from regression analysis).

Table 5 .

Summary of Multiple Regression Analysis for "Perception" Stigma-Related Barriers Predicting Personal Willingness to Seek Help $(N=84)$

\begin{tabular}{lllllll}
\hline & B & Std. Error & Beta & t & sig \\
\hline 1 & (Constant) & 1.987 & 1.201 & & 1.654 & .102 \\
Perception 2 & .388 & .147 & .287 & 2.640 & .010 \\
Perception 3 & -.130 & .174 & -.103 & -.748 & .457 \\
Perception 4 & .109 & .144 & .103 & .756 & .452 \\
Perception 5 & -.057 & .146 & -.048 & -.392 & .696 \\
Perception 6 & -.001 & .144 & -.001 & -.008 & .994 \\
Perception 7 & .256 & .174 & .184 & 1.473 & .145 \\
\hline
\end{tabular}

a. Dependent Variable: Reality-Willingness to seek help 
Together, the variables did not significantly predict willingness to seek help, $F(6,77)$ $=1.75, p=.12, \mathrm{R}^{2}=.12$. Whether or not Service Members believe their peers think seeking help is a sign of a "personal weakness" was the only significant predictor in the model, $t(77)$ $=2.64, p=.01, \beta=.287$. If Service Members' believed their peers would lose faith in another soldier who has sought mental health treatment was not significant, $t(77)=-.75, p=$ $.46, \beta=-.103$, the belief Service Members peers think leaders would treat a Soldier "differently" if they have sought mental health treatment was not significant, $t(77)=.756, p$ $=.45, \beta=.103$, whether Service Members believe their peer feel it would be "too embarrassing" to seek mental health treatment was not significant, $t(77)=-.39, p=.70$, $\beta=-.048$, whether or not Service Members believe that their peers think seeking mental health treatment might harm their career was not significant, $t(77)=-.01, p=.99, \beta=-.001$, and finally, if the Service Members' peers think that mental health care does, or does not "work", was not a significant barrier, $t(77)=1.47, p=.15, \beta=.184$.

The models revealed that Service Members own perceptions about stigma-related barriers to care significantly predict willingness to seek help, with the "reality" perceptions of barriers accounting for $20 \%$ of the total variance. Further, for the "reality" barriers, those who indicated that seeking help is a "personal weakness" rather than a personal strength, were less likely to indicate an interest in seeking help, $t(77)=3.78, p<.001, \beta=.427$, and those Service Members who believed their peers regard seeking help more as a "personal weakness" than a personal strength, indicated a lower interest in seeking help themselves if they had an emotional, relational, or psychological issue, $t(77)=2.64, p=.01, \beta=.287$. 


\section{Exploratory Analyses}

Differences by Demographic Variables. One-way ANOVA models were used to examine differences in willingness to seek help by ethnicity, marital status, rank, total years of service in the military, and previous mental health treatment. Demographic categories were combined due to low numbers of variability. See Table 6 for means and standard deviations. After conducting exploratory analyses, no differences between demographic subgroups were detected in terms of willingness to seek help. Failure to detect differences in willingness to seek help amongst various demographic cohorts is likely related to unequal group sizes, and is further evidenced by the minimal differences between mean scores. Table 6.

Differences in Willingness to Seek Help by Participant Characteristics

\begin{tabular}{|c|c|c|c|}
\hline Demographic Variables & & $n$ & $M($ SD) \\
\hline & $\begin{array}{l}\text { E1-E9 } \\
\text { Officer }\end{array}$ & $\begin{array}{l}58 \\
23\end{array}$ & $\begin{array}{c}4.39(2.16) \\
4.67(1.77)\end{array}$ \\
\hline Total Years in Service & $\begin{array}{r}1-9 \\
10+\end{array}$ & $\begin{array}{l}40 \\
41\end{array}$ & $\begin{array}{c}4.64(1.97) \\
4.18(2.10)\end{array}$ \\
\hline Race/Ethnicity & $\begin{array}{l}\text { White } \\
\text { Other }\end{array}$ & $\begin{array}{l}51 \\
29\end{array}$ & $\begin{array}{l}4.42(2.13) \\
4.57(2.01)\end{array}$ \\
\hline Marital Status & $\begin{array}{r}\text { Single } \\
\text { Married }\end{array}$ & $\begin{array}{l}44 \\
37\end{array}$ & $\begin{array}{l}4.31(2.13) \\
4.72(2.00)\end{array}$ \\
\hline Previous Mental Health Treatment & $\begin{array}{l}\text { Yes } \\
\text { No }\end{array}$ & $\begin{array}{l}19 \\
63\end{array}$ & $\begin{array}{l}4.11(2.16) \\
4.54(2.01)\end{array}$ \\
\hline
\end{tabular}




\section{Discussion}

The purpose of this study was to investigate the influence of stigma-related barriers to care on willingness to seek psychological help for Service Members. The second aim of the study was to explore the applicability of a social norms approach to help seeking behavior for military personnel. To accomplish this, barriers that have been linked to a decline in helpseeking behavior for Service Men and Women through previous studies of this nature (Hoge, 2004; Tanielian \& Jaycox, 2008) were developed into a questionnaire in order to assess the saliency and impact of mental health barriers to care for National Guard soldiers, while also gauging the participants' perception of how their peers might respond to the perceived barriers to mental health treatment.

In the section that follows, the influence of Service Members' perceptions about the way their peers view stigma-related barriers to care will be investigated. Specifically, whether these perceptions impact Service Members' own beliefs about seeking psychological care will be explored. The question of whether or not stigma-related barriers to care influence Service Members' willingness to seek psychological treatment will be investigated, as well as whether a Service Member's own view, or the beliefs about their peers' perceptions of seeking psychological care influence willingness to seek help. Findings from exploratory analyses on the influence of personal characteristics on willingness to seek help for Service Members will be reviewed. Finally, implications of the findings will be addressed in terms of the role that stigmatized beliefs towards help seeking in the military influence the pursuit of psychological care, and particularly whether peer influence is a significant factor for Service Members deciding whether or not to seek mental health treatment. Limitations of the study will also be examined. 
Are Service Members' perceptions about stigma-related barriers to care related to their beliefs of their peers' views of the same barriers?

It was hypothesized that for each stigma-related barrier to care, Service Members' own perceptions would be positively correlated with the perception of peers' beliefs on the same barrier to seeking mental health treatment. This hypothesis was supported for each of the seven stigma-related barriers to care. For each barrier, Service Members' own beliefs were significantly and positively correlated with perceptions of their peers' beliefs, with Pearson's Correlation Coefficients ranging from moderate (.31) to strong (.67). Of the seven barriers, the idea that Service Members would be more likely to lose confidence in someone who has sought psychological help, if they believe that a peer would do the same, had the strongest correlation between personal views and perceptions of peers' beliefs. Personal views and perceptions of peers' beliefs that health care "does not work", and whether Service Members would seek help if they had an emotional, relational, or psychological problem were also strongly related to their peers' perceptions. Thus, the results of this study indicate that the individual views of stigma-related barriers to psychological care are significantly related to the perceived attitudes of Service Members' peer group (other Service Members). Do stigma-related barriers to care influence a Service Members' willingness to seek help?

One stigma-related barrier, the belief that seeking help from a mental health professional is a sign of a personal weakness, consistently showed a significant and positive relationship with help seeking status. Service Members' who held the view that mental health treatment is a sign of a personal weakness were less likely to indicate a desire to seek psychological care themselves, and this stigma-barrier was also significantly correlated with personal willingness to seek help. The belief that Service Members' peers view seeking help 
as a personal weakness rather than a personal strength was also significantly correlated with personal willingness to seek help, as was the perception of peers' willingness to seek treatment. In terms of the stigma-related barrier of viewing help-seeking as a personal strength versus a personal weakness, Service Members' perceptions of their peers' beliefs about this barrier emerged as having the strongest relationship with willingness to seek help, compared to all other variables. It should be noted that the response options for the reality and perception versions of this item differed from the rest of the measures (See Appendix A, questions 3 and 4) which may have influenced participants' responses.

Do Service Members' perceptions of their peers' beliefs or personal beliefs about barriers to seeking mental health care predict willingness to seek psychological help?

To address the question of whether Service Members own perceptions, or perceptions' of their peers' beliefs about stigma-related barriers to care predict help-seeking status, separate models were utilized to determine the impact of personal and perceived beliefs on willingness to seek help. Results indicated that $20 \%$ of the variance in willingness to seek help could be accounted for by the personal views of Service Members towards the barriers in question, while there was no overall significance in a model examining whether help-seeking status is significantly influenced by a Service Members' perceptions of peers' beliefs. Further, as mentioned previously, when individual barriers were assessed for their correlation with willingness to seek help, one reality barrier (whether seeking help is a sign of a personal or strength) was significantly related to help-seeking, while two of the perception barriers (if peers perceive seeking help as a weakness or strength, and perception of peers' willingness to help) were. Thus, when Service Members are considering whether or not to seek help, their own perceptions and attitudes towards stigma-related barriers to care 
are predictive of personal willingness to seek help, but a significant relationship also exists between personal help-seeking status, and perceptions' of peers' views towards certain stigma barriers.

Is willingness to seek psychological care influenced by personal characteristics?

Differences in willingness to seek help were investigated in terms of various demographic variables including race, marital status, rank, total years of military service, and previous mental health treatment. Not one of these factors significantly influenced willingness to seek help in the sample of Service Members assessed. In terms of race, this was consistent with previous findings in a similar study assessing college students' willingness to seek psychological care, but the finding that there were no differences amongst those who have sought treatment in the past is not (Conley, 2011).

\section{Next Steps and Implications}

According to the findings of this study, Service Members' perceptions of stigmarelated barriers to care did account for a higher variance in willingness to seek help compared to perceptions of peers' beliefs about the same barriers. Further, Service Members' beliefs about the barriers were strongly and positively correlated with their perceptions of peers' beliefs. However, some perception barriers emerged as significantly and positively related to personal help-seeking status. The results of this study provide inconclusive findings on whether the social norms approach would be an effective means for increasing willingness to seek psychological care for Service Members for two reasons. For one, the social norms approach is dependent upon the discrepancy between an individual's beliefs and the perception of their peers' beliefs of the concept in question (Berkowitz, 2004). According to this study, Service Members do not endorse the idea that their peers have a healthier or 
different attitude towards seeking mental health treatment above their own views. However, two of the perception barriers were significantly related to help-seeking status, and only one of the reality barriers was. Further, when examining predictive status of the reality and perception barriers, the findings show that Service Members own perceptions of stigmarelated barriers better account for the variability in help-seeking; yet only $20 \%$ of total variance is accounted for. Thus, more research is needed to determine whether Service Members are better influenced by their own beliefs or their peers' beliefs when it comes to seeking psychological care, and whether a social norms campaign would be effective for this group.

A recent and related study on stigma and barriers to care for military personnel uncovered that Service Members are more likely to be influenced by their own stigmatized views of psychological care compared to how they perceive others (leaders, fellow Service Members) would view them for pursuing treatment. Although perceived stigma was highly endorsed in the study, it was found to be less influential in one's decision to seek help, compared to personal views of stigma-related barriers (Kim, Britt, Riveiere, Adler, 2011). Thus, similar to the outcomes of the current study, Service Members' personal views were better predictive of help-seeking status compared to perceptions of others beliefs, and yet perceptions of peers' views were found to be significantly related to personal help-seeking status.

According to these findings and similar research on help-seeking in the military, an effective way to reduce stigma and increase treatment adherence for Service Members may be to target the personal costs of seeking care, both in relation to individual views of helpseeking, and perceptions of peers' beliefs. Researchers have investigated and proposed a few 
measures to address this issue, such as targeting and dispelling the idea that seeking psychological treatment is a sign of "weakness", and eradicating beliefs that an individual with psychological problems is in some way responsible for their diagnosis. Researchers believe deterrents to seeking help can be reduced through the use of psychoeducation, cognitive restructuring, and teaching soldiers to feel "empowered" for seeking treatment (Dickstein, Vogt, Handa, \& Litz, 2010). These are certainly steps in the right direction, but it is essential that the fundamental aspects of why stigma associated with mental health treatment is so prevalent in the Armed Forces be taken into consideration.

One place to start is by comparing the military to other groups that have been investigated in terms of peer and individual perceptions of seeking help. Conley (2011) found that college students do in fact misperceive the perceptions their peers have in terms of willingness to seek psychological care. College students tend to believe that their peers have more negative perceptions of mental illness and treatment than they actually do. Findings such as these highlight the difference between beliefs of college students and Service Members in terms of help-seeking behavior. Specifically, Conley's study demonstrated that college students tend to perceive that their peers are not likely to be accepting of the idea of seeking psychological care, while the college students themselves were in fact generally supportive of mental health treatment. Another difference between the participants in the current study and Conley's is the amount of familiarity with the reference group in question. The students that Conley surveyed were in-coming freshman from various universities, and were unlikely to be well-acquainted with the other students they were considering as their peers or reference group. This is different for the participants of the current study, being that most of the individuals assessed had been in the Service for at least a year, and likely 
experienced extended periods of interaction and exposure with those they would consider their peer reference group- other Service Members. When viewing the outcomes of the study with these discrepancies in mind, the question becomes, what are the differences between military personnel and college students in their perceptions of help-seeking? Particularly, why is it that college students have "healthier" views towards seeking help, compared to Service Members?

Throughout history, there has been recognition of the idea of "Warrior Culture" and the unique identity that Service Members adapt as they live and work by military standards and ideals (Danish \& Antonides, 2009). Is the "Warrior Culture" affecting the way that Service Members view the consequences of seeking help? One of the main tenets of the United States Army is the "Warrior Ethos", which guides Service Members to "place the mission first" and "never accept defeat". In the U.S. Army's "Soldier's Creed" it says that soldiers are to be "mentally tough". These values lend themselves to the belief that mental health problems and psychological distress are barriers to being an optimal and efficient soldier. Many researchers have discussed the idea of military culture and the influence it has on the pursuit of mental health treatment in the past (Dickstein et al., 2010; Hoge, 2004; Tanielien \& Jaycox, 2008), yet only in terms of how it perpetuates this issue; not from a solution oriented perspective. There is a need then for future research on how stigma can be eradicated at an organizational or cultural level within the Armed Forces. The next step is to determine how to target the negative views of psychological care that are developed through membership in this special population. Future research should address how such widely held beliefs can be changed in an environment that fosters the necessity of mental fitness and personal strength. This pursuit involves a discussion of the current regulations and standards 
put forth by the U.S. Military concerning mental health status and fitness for duty, as well as the policies currently in place for reporting the use of psychological services by Service Members. Another area that would benefit from exploration is how leaders at both the unit and command level can help to change the culture of mental health awareness and the rate of treatment utilization among troops. Encouraging Service Members to treat emotional and psychological issues with the same care as they would other physical health concerns would certainly be a great start.

\section{Limitations}

The limitations of the study are namely in the generalizability of the outcomes. The sample consists of soldiers from National Guard units from the state of Virginia. The experiences of members of the National Guard are likely to vary in comparison to Active Duty components of the Armed Forces, as well as Veterans who have separated from service. Another limitation of the study is in the demographic variables that were not collected, including age and gender. Without information on these variables, it limits the ability to aptly apply the findings in terms of differences between sub-groups of the military. Finally, peer influence may have been better gauged in terms of the participants' responses to the peer perception questions. The data were gathered at Yellow Ribbon events where numerous Service Members would have been present, possibly causing some interference in how honest respondents were when discussing their perceptions of peers' beliefs. Future studies should address this issue by gathering data from participants in a neutral environment where influence from one's peer group might be minimized. Finally, future studies would benefit from gathering data on the type of mental health services that Service Members have utilized in the past, as well as treatment options they would consider utilizing in the future. For 
instance, it is not clear whether those who have sought treatment in the past did so from a mental health provider, a chaplain, a VA Hospital, etc. Knowing where Service Members are seeking help, as well as their preference for where they would go should they choose to do so in the future, would provide a stronger understanding of the nature of help-seeking in the military.

\section{Final Thoughts}

Although prevalent, the stigmatized views towards help-seeking in the military are not unchangeable. However, it will take a unified effort on the part of mental health professionals, military leaders, and policy makers to begin altering the aspects of military culture that have led many Service Members to believe that psychological treatment is not a viable option if they are in need of help. 


\section{List of References}

Berkowitz, A. (2004). An overview of the social norms approach. In L. Lederman, L. Stewart, F. Goodhart \& L, Laitman (Eds.), Changing the culture of college drinking: A socially situated prevention campaign, Hampton Press.

Byrne, P. (2001). Psychiatric stigma. British Journal of Psychiatry, 178, 281-284.

Conley, K. A. (2011). The influence of perception on willingness to seek help among college freshmen. (Unpublished doctoral dissertation). Virginia Commonwealth University, Rickmond, Virginia.

Corrigan, P. (2004). How stigma interferes with mental health care. American Psychologist, 59(7), 614-625.

Corrigan, P. W., Markowitz, F. E., \& Watson, A. C. (2004). Structural levels of mental illness stigma and discrimination. Schrizophenia Bulletin, 30, 481-491.

Corrigan, P. W. \& Penn D. L. (1999). Lessons from social psychology on discrediting psychiatric stigma. American Psychologist, 54, 765-776.

Danish, S. J. \& Antonides, B. J. (2009). What counseling psychologists can do to help returning veterans. Counseling Psychologist, 37(8), 1076-1089.

Dickstein, D. D., Vogt, D. S., Handa, S., \& Litz, B.T. (2010). Targeting self-stigma in returning military personnel and veterans: A review of intervention strategies. Military Psychology, 22, 224-236.

Goffman, E. (1963). Stigma: Notes on the Management of a Spoiled Identity. New York: Simon and Schuster.

Gorman, L. A., Blow, A. J., Ames, B. D., \& Reed, P. L. (2011). National Guard families after combat: Mental health, use of mental health services, and perceived treatment barriers. Psychiatric Services, 62(1), 28-34. Retrieved from http://ps.psychiatriconline.org

Greden, J. F., Valenstein, M., Spinner, J., Blow, A., Gorman, L. A., Dalack, G. W., Marcus, S., \& Kees, M. (2010). Buddy-to-Buddy, a citizen soldier peer support program to counteract stigma, PTSD, depression, and suicide. Annals of the New York Academy of Sciences, 1208, 90-97. doi: 10.1111/j.1749-6632.2010.05719.x

Haines, M. \& Spear, S.F. (1996). Changing the perception of the norm: A strategy to decrease binge drinking among college students. Journal of American College Health, 45, 134140. 
Hancock, L., Vatalaro Hill, K. and Barber, J. (2010). Using audience response technology in brief live interactive normative group (BLING) sessions to reduce high-risk drinking in first year college students. College Health in Action, 49 (3), 14-15.

Hoge, C. W., Castro, C. A., Messer, S. C., McGurk, D., Cotting, D. I., \& Koffman, R. L. (2004). Combat duty in Iraq and Afghanistan, mental health problems, and barriers to care. New England Journal of Medicine, 351, 13-22.

Kim, P.Y., Britt, T. W, Klocko, R. P., Riviere, L. A., \& Adler, A. B. (2011). Stigma, negative attitudes about treatment, and utilization of mental health care among soldiers. Military Psychology, 23, 65-81.

Kim, P. Y., Thomas, J. L., Wilk, J. E., Castro, C. A., \& Hoge, C. W. (2010). Stigma, barriers to care, and use of mental health services among active duty and National Guard soldiers after combat. Psychiatric Services, 61(6), 572-588. Retrieved from http://ps.psychiatriconline.org

Nash, W. P., Silva, C., \& Litz, B. (2009). The historic origins of military and veteran mental health stigma and the stress injury model as a means to reduce it. Psychoatric Annals, 39, 789-794.

Neighbors, C., Lostutter, T. W., Whiteside, U., Fossos, N., Walker, D. D., \& Larimer, M. E. (2007). Injunctive norms and problem gambling among college students. Journal of Gambling Studies, 23(3), 259-273.

Perkins, H.W. \& Berkowitz, A.D. (1986). Perceiving the community norms of alcohol use among students: Some research implications for campus alcohol education programming. International Journal of the Addictions, 21, 961-976.

Perkins, H.W. \& Craig, DA (2002). A Multi-faceted Social Norms Approach to Reduce High-Risk Drinking: Lessons from Hobart and William Smith Colleges. Newton, MA: The Higher Education Center for Alcohol and Other Drug Prevention.

Pietzrak, R., Johnson, D., Goldstein, M., Malley, J., \& Southwick, S. (2009). Perceived stigma and barriers to mental health care utilization among OEF-OIF veterans. Psychiatric Services, 60(8), 1118-1122.

Schulze, B., Richter-Werling, M., Matschinger, H., \& Angermeyer, M. C. (2003). Crazy? So What! Effects of a school project on students' attitudes towards people with schizophrenia. Acta Psychiatr Scand, 107, 142-150.

Stecker, T., Fortney, J. C., \& Sherbourne, C. D. (2011) An intervention to increase mental health treatment engagement among OIF veterans: A pilot trial. Military Medicine, $176,613-619$. 
Tanielian, T., \& Jaycox, L. (Eds). (2008). Invisible wounds of war: Psychological and cognitive injuries, their consequences and services to assist recovery. Santa Monica, CA: RAND

United States Department of Defense, Defense Health Board, Task Force on Mental Health. (2007). An achievable vision: Report of the department of defense task force on mental health. Retrieved from http://www.health.mil/dhb/mhtf/mhtf-report-final.pdf

U.S. Department of Defense. (2011). Medical standards for appointment, enlistment, or induction in the military services (DoD Publication No. 6130.03). Retrieved from http://www. dt ic.mil/whs/directives/corres/pdf/613003p.pdf

Vogel, D. L., Wade, N. G., \& Hackler, A. H. (2007). Perceived public stigma and the willingness to seek counseling: The mediating roles of self-stigma and attitudes toward counseling. Journal of Counseling Psychology, 54(1), 40-50.

Warner, C. H., Appenzeller, G. N., Grieger, T., Belenkiy, S., Breitbach, J., Parker, J., Waner, C. M., \& Hoge, C. (2011). Importance of anonymity to encourage honest reporting in mental health screening after combat deployment. Archives of General Psychiatry, 68, 1065-1071.

Wright, K. M., Cabrera, O. A., Bliese, P. D., Adler, A. B., Hoge, C. W., \& Castro, C. A. (2009). Stigma and barriers to care in soldiers postcombat. Psychological Services, 6, 108116. doi: $10.1037 / \mathrm{a} 0012620$ 


\section{Appendix A}

1. How do you think MOST soldiers would respond to this statement? If I had an emotional, relational, or psychological problem, I'd seek help from a mental health professional.

$1=$ Strongly Disagree

$2=$ Disagree

$3=$ Somewhat Disagree

4=Neither Agree nor Disagree

$5=$ Somewhat Agree

$6=$ Agree

7=Strongly Agree

2. What is YOUR response to the following statement? If I had an emotional, relational, or psychological problem, I'd seek help from a mental health professional.

$1=$ Strongly Disagree

$2=$ Disagree

$3=$ Somewhat Disagree

4=Neither Agree nor Disagree

$5=$ Somewhat Agree

$6=$ Agree

7=Strongly Agree

3. If 1 is a sign of personal weakness and 7 is a sign of personal strength, how would MOST soldiers rate getting help from a mental health professional?

$1=$ Very weak

$2=$ Weak

$3=$ Somewhat weak

$4=$ Neither strong nor weak

$5=$ Somewhat strong

$6=$ Strong

$7=$ Very strong

4. If 1 is a sign of personal weakness and 7 is a sign of personal strength, how do YOU rate getting help from a mental health professional?

$1=$ Very weak

$2=$ Weak

$3=$ Somewhat weak

$4=$ Neither strong nor weak

$5=$ Somewhat strong

$6=$ Strong

$7=$ Very strong 
5. Knowing that a peer has sought help from a mental health professional, MOST soldiers would lose confidence in that soldier.

$1=$ Strongly Disagree

$2=$ Disagree

$3=$ Somewhat Disagree

4=Neither Agree nor Disagree

5=Somewhat Agree

$6=$ Agree

$7=$ Strongly Agree

6. Knowing that a peer has sought help from a mental health professional, I would lose confidence in that soldier.

$1=$ Strongly Disagree

$2=$ Disagree

3=Somewhat Disagree

$4=$ Neither Agree nor Disagree

$5=$ Somewhat Agree

$6=$ Agree

$7=$ Strongly Agree

7. Knowing a soldier sought mental health services, MOST leaders would treat the soldier differently.

$1=$ Strongly Disagree

$2=$ Disagree

$3=$ Somewhat Disagree

$4=$ Neither Agree nor Disagree

$5=$ Somewhat Agree

$6=$ Agree

7=Strongly Agree

8. As a leader, knowing that a soldier in my command sought mental health services, I would treat the soldier differently.

$1=$ Strongly Disagree

$2=$ Disagree

$3=$ Somewhat Disagree

$4=$ Neither Agree nor Disagree

5=Somewhat Agree

$6=$ Agree

7=Strongly Agree 
9. How do you think MOST soldiers would respond to this statement? It would be too embarrassing for me to seek help from a mental health professional.

$1=$ Strongly Disagree

$2=$ Disagree

$3=$ Somewhat Disagree

4=Neither Agree nor Disagree

5=Somewhat Agree

$6=$ Agree

$7=$ Strongly Agree

10. What is YOUR response to this statement? It would be too embarrassing for me to seek help from a mental health professional.

$1=$ Strongly Disagree

$2=$ Disagree

$3=$ Somewhat Disagree

4=Neither Agree nor Disagree

5=Somewhat Agree

$6=$ Agree

7=Strongly Agree

11. How do you think MOST soldiers would respond to this statement? It would harm my career to seek help from a mental health professional.

$1=$ Strongly Disagree

$2=$ Disagree

$3=$ Somewhat Disagree

$4=$ Neither Agree nor Disagree

5=Somewhat Agree

$6=$ Agree

7=Strongly Agree

12. What is YOUR response to this statement? It would harm my career to seek help from a mental health professional.

$1=$ Strongly Disagree

$2=$ Disagree

$3=$ Somewhat Disagree

$4=$ Neither Agree nor Disagree

$5=$ Somewhat Agree

$6=$ Agree

$7=$ Strongly Agree 
13. How do you think MOST soldiers would respond to this statement? Mental health care doesn't work.

$1=$ Strongly Disagree

$2=$ Disagree

$3=$ Somewhat Disagree

$4=$ Neither Agree nor Disagree

5=Somewhat Agree

$6=$ Agree

$7=$ Strongly Agree

14. What is YOUR response to this statement? Mental health care doesn't work. $1=$ Strongly Disagree

$2=$ Disagree

$3=$ Somewhat Disagree

$4=$ Neither Agree nor Disagree

$5=$ Somewhat Agree

$6=$ Agree

$7=$ Strongly Agree 


\section{Appendix B}

1. What is YOUR response to the following statement? If I had an emotional, relational, or psychological problem, I'd seek help from a mental health professional.

1=Strongly Disagree

$2=$ Disagree

3=Somewhat Disagree

$4=$ Neither Agree nor Disagree

$5=$ Somewhat Agree

$6=$ Agree

7=Strongly Agree

2. How do you think MOST soldiers would respond to this statement? If I had an emotional, relational, or psychological problem, I'd seek help from a mental health professional.

$1=$ Strongly Disagree

$2=$ Disagree

3=Somewhat Disagree

$4=$ Neither Agree nor Disagree

$5=$ Somewhat Agree

$6=$ Agree

7=Strongly Agree

3. If 1 is a sign of personal weakness and 7 is a sign of personal strength, how do YOU rate getting help from a mental health professional?

$1=$ Very weak

$2=$ Weak

$3=$ Somewhat weak

$4=$ Neither strong nor weak

$5=$ Somewhat strong

$6=$ Strong

$7=$ Very strong

4. If 1 is a sign of personal weakness and 7 is a sign of personal strength, how would MOST soldiers rate getting help from a mental health professional?

$1=$ Very weak

$2=$ Weak

$3=$ Somewhat weak

$4=$ Neither strong nor weak

$5=$ Somewhat strong

$6=$ Strong

$7=$ Very strong 
5. Knowing that a peer has sought help from a mental health professional, I would lose confidence in that soldier.

$1=$ Strongly Disagree

$2=$ Disagree

$3=$ Somewhat Disagree

4=Neither Agree nor Disagree

$5=$ Somewhat Agree

$6=$ Agree

$7=$ Strongly Agree

6. Knowing that a peer has sought help from a mental health professional, MOST soldiers would lose confidence in that soldier.

$1=$ Strongly Disagree

$2=$ Disagree

$3=$ Somewhat Disagree

$4=$ Neither Agree nor Disagree

5=Somewhat Agree

$6=$ Agree

7=Strongly Agree

7. As a leader, knowing that a soldier in my command sought mental health services, I would treat the soldier differently.

$1=$ Strongly Disagree

$2=$ Disagree

$3=$ Somewhat Disagree

4=Neither Agree nor Disagree

$5=$ Somewhat Agree

$6=$ Agree

7=Strongly Agree

8. Knowing a soldier sought mental health services, MOST leaders would treat the soldier differently.

$1=$ Strongly Disagree

$2=$ Disagree

$3=$ Somewhat Disagree

$4=$ Neither Agree nor Disagree

5=Somewhat Agree

$6=$ Agree

$7=$ Strongly Agree 
9. What is YOUR response to this statement? It would be too embarrassing for me to seek help from a mental health professional.

$1=$ Strongly Disagree

$2=$ Disagree

$3=$ Somewhat Disagree

4=Neither Agree nor Disagree

5=Somewhat Agree

$6=$ Agree

$7=$ Strongly Agree

10. How do you think MOST soldiers would respond to this statement? It would be too embarrassing for me to seek help from a mental health professional.

$1=$ Strongly Disagree

$2=$ Disagree

$3=$ Somewhat Disagree

4=Neither Agree nor Disagree

5=Somewhat Agree

$6=$ Agree

7=Strongly Agree

11. What is YOUR response to this statement? It would harm my career to seek help from a mental health professional.

$1=$ Strongly Disagree

$2=$ Disagree

$3=$ Somewhat Disagree

4=Neither Agree nor Disagree

$5=$ Somewhat Agree

$6=$ Agree

7=Strongly Agree

12. How do you think MOST soldiers would respond to this statement? It would harm my career to seek help from a mental health professional.

$1=$ Strongly Disagree

$2=$ Disagree

$3=$ Somewhat Disagree

$4=$ Neither Agree nor Disagree

5=Somewhat Agree

$6=$ Agree

$7=$ Strongly Agree 
13. What is YOUR response to this statement? Mental health care doesn't work.

$1=$ Strongly Disagree

2=Disagree

3=Somewhat Disagree

$4=$ Neither Agree nor Disagree

$5=$ Somewhat Agree

$6=$ Agree

7=Strongly Agree

14. How do you think MOST soldiers would respond to this statement? Mental health care doesn't work.

$1=$ Strongly Disagree

$2=$ Disagree

$3=$ Somewhat Disagree

$4=$ Neither Agree nor Disagree

$5=$ Somewhat Agree

$6=$ Agree

7=Strongly Agree 


\section{Appendix C}

Which ethnic/racial group do you best identify with?

\begin{tabular}{|c|c|c|c|c|c|}
\hline $\begin{array}{l}\text { Black/African-American } \\
\text { Indian }\end{array}$ & \multicolumn{2}{|c|}{ Asian/Asian-American } & \multicolumn{2}{|c|}{ Hispanic/Latino } & American \\
\hline Middle Eastern & \multicolumn{2}{|c|}{ White, non-Hispanic } & \multicolumn{2}{|c|}{ Pacific Islander } & Other \\
\hline Marital Status: Single & Married & Divorced & Separated & Wic & ow/Widower \\
\hline $\begin{array}{c}\text { What is your rank? } \\
\text { O5 + }\end{array}$ & E1- E3 & E4 - E6 & E7 - E9 & & $-\mathrm{O} 4$ \\
\hline
\end{tabular}

What is your current MOS and field?

$\begin{array}{lllll}\text { Total years in service: } 1-4 & 5-9 & 10-15 & 16-20 & 20+\end{array}$

Have YOU ever sought help from a mental health professional? $\quad$ Yes $\quad$ No

Have you sought mental health services in the past 6 months? $\quad$ Yes

$\begin{array}{lll}\text {...in the past } 12 \text { months? } & \text { Yes }\end{array}$

In general, of the soldiers that you know, how many of them do you think have sought help from a mental health professional?

None $\quad 1-2 \quad 3$ or more

Of the soldiers that you know who have sought help from a mental health professional, how many do you think have done so in the past 6 months?

None $\quad 1-2 \quad 3$ or more

...in the past 12 months?

None $\quad 1-2 \quad 3$ or more 


\section{Vita}

Janette Hamilton was born on September $26^{\text {th }}, 1986$, in St. Louis, Missouri. She graduated from Kirkwood High School in 2005, in Kirkwood, Missouri. Janette attended Fontbonne University, where she studied Psychology and Sociology. She graduated Cum Laude, with a Bachelor of Arts in Psychology in 2009. Janette received a Master's of Arts in Psychology from The State University of New York, College at Brockport, in 2011, and is currently pursuing her doctorate in Counseling Psychology at Virginia Commonwealth University. 